\title{
When parties collide: The impact of intra-EP dynamics on the delegation patterns in the EU.
}

\author{
Anastasia Ershova \\ Department of Government, London School of Economics and Political Science
}

\author{
Sebastian Adrian Popa \\ Politics Department, Newcastle University \\ MZES, University of Mannheim
}

\begin{abstract}
The EP plays a crucial role in defining the power of implementing agencies in the EU. In this article, we move beyond the 'unitary actor' approach to the EP and examine the influence of intra-parliamentary dynamics on the delegation patterns in the Union. We maintain that party polarisation as well as the level of policy salience shape delegation patterns in the EU. Reflecting the differences between political elites, increasing party polarisation motivates the EP to curtail the prospect of bureaucratic drift when delegating power. Lacking effective control mechanisms over the supranational agency, the EP hinders the extent of delegated power if the Commission oversees the policy. In contrast to the extant literature, we do not find policy salience to be influential for the EP's delegation decisions. We test these conjunctions using data from the Euromanifesto project and the dataset on delegation dynamic in the Union.
\end{abstract}

Keywords: Delegation, Euromanifesto, European Commission, European Parliament, Party Polarisation

\section{Word count: 7992}

Corresponding author: Anastasia Ershova, Department of Government, London School of Economics and Political Science, Houghton street, London, the UK.

Email: a.ershova@1se.ac.uk 


\section{Introduction}

Do party stances play a role in delegation decision in the European Parliament (EP)? To what extent does issue salience strengthen motivations of the EU legislators to delegate more power to the agent? These questions go to the very heart of the policymaking process in the European Union (EU). With the expansion of the co-decision and its subsequent transformation into Ordinary Legislative Procedure (OLP), the role of the EP has increased in shaping the outcome of decision-making. In this new environment, the internal dynamic inherent to the EP has attracted great scholarly attention, seeking to grasp to what extent the new powers may have shaped behaviour and the preferences of the institution.

This paper brings in a new perspective on the role of the preferences of the European parties. Specifically, we investigate to what extent EU delegation patterns are influenced by the magnitude of party polarisation and salience the EP parties attach to policies. Extant findings suggest that party polarisation affects voting behaviour and the policymaking process (Sinclair, 2006; Thomson, 2008), whilst policy salience shapes behaviour and choices made by legislative principals across polities (Bawn, 1997; Thomson, 2011). Here, we link the insights from these studies to the literature discussing the extent of agency during the final stage of the EU policymaking process. We portray the process of delegation as a choice the EU principals - the Council of Ministers and the parties in the EP-make when selecting how much power to grant to either the European Commission or the national administrations (NAs), acting as implementing agents. ${ }^{1}$ Unlike previous studies, we do not treat the EP as a unitary actor and rather investigate how the EP's internal dynamics shape the extent of delegated powers to and across agencies. Hence, we move beyond Bendor and Meirowitz (2004) who analyse the degree to which risk aversion affects the decision to delegate the power to the agent or not. Following the PA framework, we argue that the stakes associated with a given policy are likely to incentivise the principals to avoid uncertainty during the policy implementation stage. We theorise that the principals should restrict the power of the implementing agency in such cases. To do so, principals will aim to reduce the extent of unforeseen deviations from the agreed measures by limiting the ability of the implementing agency to shape the policy during the implementation stage. Hence, the EP parties would limit the amount of power they are willing 
to delegate to the agents and would seek to impose additional constraints on the agency power within the legislative act.

There are two likely scenarios in which the principals will seek to act in these ways: when they attach high degrees of policy salience and when they delegate policies under conditions of high preference polarisation. Firstly, if European political parties attach a high degree of importance to a given policy, they are likely to constrain the implementation agency to prevent policy drifts. Secondly, as high polarisation leads to a gridlock in decision-making, once a policy compromise is reached, the decision-makers would prefer to reduce the uncertainty about policy outcomes in order to avoid reigniting the conflict. They can do so by ensuring that the agency responsible for the implementation process adheres to the agreed policy as much as possible. Therefore, the extent of delegation is also likely to be more constrained whenever the policy has been approved by the polarised principals. In both scenarios, the degree of delegation also depends on the ability of the principals to impose ex ante controls on the agents in charge of implementation (Bendor \& Meirowitz, 2004). We anticipate that the EP parties, acting as principals, are more sceptical about delegating power when agents are harder to control. In our specific case this implies that the delegated power is more limited when the Commission oversees the implementation due to limited ex post control opportunities over this agency, which in turn undermines the efforts to hinder the uncertainty that the EP faces.

Unlike previous studies examining coalition formation and influence of party polarisation on the success of the EP in shaping the content of the legislative act (Hagemann \& Høyland, 2010), we rather focus on the consequences of delegation that affects the implementation stage. By moving beyond a unitary understanding of the EP in the EU decision-making process, this paper represents the first attempt to understand how intra-legislative party competition and conflict transcend the initial stages of the decisionmaking process. We show how constellations of party positions within the EP impact the decision-making process beyond the adoption or rejecting legislation, hence indirectly shaping policy outcome. Furthermore, by developing a systematic assessment of how political contestation in the Parliament affects the agency power, we contribute to the growing literature on politicisation of decision-making in the EU. By shifting 
the focus of the discussion from the need to approve legislation to the later stage of the decision-making, we trace how political motivations permeate through various stages of the process. Lastly, by combining two prominent datasets, we empirically assess how party polarisation and issue salience shape delegation in the Union, thus contributing to the extant literature on the collective decision-making.

Our results suggest a strong negative effect of polarisation on the extent of delegated powers. We also find that the delegated powers are more constrained when polarisation increases and when the Commission acts as an implementing agent.

\section{Delegation and salience}

The decision-making process in the EU is complex. However, only a subset of the extant studies focuses on the delegation choice made in the Union. These contributions rely on the PA framework to examine the forms of indirect governance and relationship between political principals and various bureaucratic agencies (Huber \& Shipan, 2002). This perspective maintains that the principals delegate power to the agent for a specific task, and in doing so they seek to reduce transaction and decision-making costs and to ensure credible commitment (Majone, 2001; Tallberg, 2002). Therefore, an expectation generated by the PA framework postulates that the principal is likely to rely on the cost-cutting logic, while maintaining a certain degree of control over the agency to prevent bureaucratic drift (Epstein \& O'Halloran, 1994). However, these studies suggest that politics of delegation is not only about choice of the agency per se, but also about the extent of power the principals are willing to transfer to the agency they have selected. Studies of the US Congress show that the extent of the intra-principals' conflict may shape the power of the agency. Epstein and O'Halloran (1999) argue that that divided government in the US is likely to result in more leeway available to the agent during policy implementation because resulting policy stability reduces the uncertainty of outcome.

If these insights are rather straightforward in the case of US politics, European studies have generated a set of rather controversial results when it comes to delegation patterns in the EU. For instance, under QMV Franchino (2007) finds that delegation dynamics in the Union are shaped by the extent of conflict 
within the Council that leads to more power available to the Commission for delegation stage. Pollack (2003), however, suggests that an intra-council discord results in more limited powers of the Commission. Furthermore, some emphasised that the incentives that drive principals' choices of delegating powers may rest on the type of agency in charge. For instance, advancing the blame-shifting argument Tallberg (2002) shows, both the Council and the EP are subject to the domestic pressures, and they thus prefer to grant powers to the EU Commission whenever a policy may yield negative consequences for their constituencies (member-states (MS)). Majone (2001) maintains that the logic of credible commitments define how power is delegated in the EU. Incorporating the idea of inter-principal conflict, he posits that delegation to an independent agency is likely to occur when the principals become more adversarial because their policy concerns will motivate them to empower a neutral broker to ensure implementation of political measures.

Overall, studies that draw on the PA framework show that delegation is influenced by agency characteristics and the political environment in which decisions are made (see Price, 1978). We should also keep in mind that the decision to delegate follows a sequential logic according to which the principals first choose the agent and then engage with the establishment of institutions and procedures allowing them to maintain control over the agent's behaviour. Divided principals may be more motivated to delegate power to avoid gridlock and ensure credible commitment to a policy (Epstein \& O’Halloran, 1994; Héritier and Moury, 2011). However, the extant contributions further underline the characteristics of a policy itself. Calvert et al. (1989, 589-590) inferred that the extent of delegation to the agency, all else being equal, decreases as the issue becomes more important for the politicians. Studies of congressional politics suggest similar patterns: the more the importance of the agent's policy decisions for the politician's constituencies increases, the more reluctant they are to grant power to the agent (Bawn, 1997). Gormley (1986) stresses that salience contributes to predicting the behaviour of political actors, citizens and bureaucrats. In their studies of Norwegian agencies and ministries, Egeberg and Trondal (2009) show that operating in more salient areas leads to more political control imposed on these actors. Scrutinising independent agencies in the Netherlands, Koop (2011) finds that agencies that operate in more salient areas are subjected to extensive accountability checks. Interestingly, only a handful of the EU-focused studies assessed to what 
extent policy importance shapes decision- and policymaking processes in the EU. Rittberger (2000) explains the extent of parliamentary support for a legislative proposal as a function of policy salience, whereas Thomson (2011) shows how issue salience defines the amount of political resources devoted to approximating the policy outcome to decision-makers' preferences. Schneider et al. (2010) argue that the salience levels motivates policymakers to opt for a compromise and give up their influence over the outcome with the aim of increasing the chance of the decision being adopted.

In the EU, both the EP and the Council decide how much power to delegate to the agency. The internal characteristics of the EP, such as parties' stances on the left-right policy are likely to influence this decision (Hageman \& Høyland, 2010) as parties tend to 'own' issues and behave as policy-seekers when the policy is highly salient for them (Klüver \& Spoon, 2015). The literature also maintains that behavioural patterns of the Members of the EP (MEPs) have been shown to follow the policies of their national parties (Hix \& Noury, 2009). Therefore, it is not unreasonable to believe that the MEPs and their parties in the EP attach policy importance in a similar manner. ${ }^{2}$ As reaching the compromise over policies on salient issues for the EP parties may prove to be challenging, once the agreement is struck, the European parties are likely to be interested in reducing the discrepancies between the realised policy and the adopted measures. One way to do so is to limit the power of the implementing agent. Hence, drawing on the extant studies (Calvert et al., 1989), salience of a policy fosters the hesitance in the political decision-makers when it comes to empowering agencies. Therefore, we posit that, in the EU context,

\section{H1: When overall salience around a given policy increases in the EP, the extent of delegated power for the implementation of a policy decreases.}

Deciding on the extent of delegation, the EP parties can empower either the Commission or the NAs to implement policies. On the one hand, delegation to the Commission is beneficial because it allows for reducing the variance in policy outcomes and to ensure that the agent is insulated from the influence of domestic political battles. The Commission is also typically viewed as a pro-EU institution, which may 
reassure policymakers about its aspirations to act as a benevolent broker of the Union. Furthermore, the logic of delegation suggests that the need to ensure credible commitments may further increase the motivation to delegate to the Commission (Majone, 2001). On the other hand, the underlying logic of delegating power to the agency implies a reduction in transaction costs (Epstein \& O'Halloran, 1999; Thomson \& Torenvlied, 2011) and is strongly influenced by the ability of principals to control the agent in charge of implementation (Bendor \& Meirowitz, 2004). Hence, the agent should be capable of ensuring an optimal policy implementation and be subjected to control mechanisms available to the principals. The Commission, despite its broad mandate, possesses constrained resources (Bouwen, 2009) and is insulated from the means of control that prevent prospective bureaucratic drift (Ershova, 2018). Furthermore, delegation to the NA, overall, offers more effective monitoring opportunities (Franchino, 2002) on the national level through the governmental oversight, thus ensuring that no significant deviations occur. ${ }^{3}$ Consequently, balancing the need to maintain control over the implementation while upholding the commitment to supranational policies, the EU principals are likely to be more reserved with the extent of power delegated to the Commission as the importance of the policy increases. Thus, we anticipate systematic differences in the extent of delegated powers across salience levels for the NAs and the Commission and hypothesise that

\section{H2: When policy salience increases, the extent of delegated powers becomes more limited when the European Commission oversees implementation.}

\section{Delegation and polarisation}

In his prominent contribution, Dalton (2008, p. 900) argues that 'party system polarization reflects the degree of ideological differentiation among parties in the system' on a specific dimension. The implications of these ideological differences have been examined closely by the scholars of the US and EU politics. Discussing party confrontation, Sinclair (2006) underlines that increasing distances between the parties shrinks the opportunities to easily reach a decision that is acceptable to all decision-makers. Under these circumstances, increasingly polarised legislature leads to an increase in deadlocks and diminishes the policy 
capabilities of executives. While the consequence of polarisation for earlier stages of the decision-making process are well established, we know very little about its impact on the implementation process. Focusing on the delegation processes in EU legislation is particularly informative because it is one of the few instances in which the consequence of legislative polarisation can be studied beyond the outcome of the vote on a given legislation.

In the EU, the decision whether a policy should be overseen by the Commission or by the NA is a matter of bargaining outcome between the EP and the Council. Extant studies have fleshed out the effects of the inter- and intra-principal's conflict on delegation patterns. Huber and Shipan (2002) show that divided principals are more likely to delegate power to the agent. ${ }^{4}$ Drawing on this, Franchino (2000) demonstrates that the extent of conflict between the EP and the Council increases the level of control the principals impose on the agent. Examining the effects of intra-Council disagreements, Pollack (2003) highlights that increasing conflict over policy outcomes is likely to hinder delegation to the Commission. Interestingly, the role of the EP internal dynamics was only studied with regard to how left-right politics should shape the type of decision of the EP (Hageman \& Høyland 2010) but not in terms of defining the extent of delegated agency powers. The OLP has expanded the powers of the EP and put it on equal footing with the Council (Aspinwall \& Schneider, 2000). Therefore, to approve a legislative act, the majority of MEPs have to express their support for the measures in the legislative proposal and obtain the support of a qualified majority in the Council. However, the EP is a complex principal, consisting of various political parties with varying preferences over policies and outcomes. In fact, extending the assumptions of the PA approach, one may maintain that parties forming the majority in the Parliament act as principals. Thus, the degree of policy disagreement between the prospective coalition partners should shape the extent of power they are willing to delegate to the agency. In the context of high polarisation, once gridlock over a policy is resolved and it is approved, we expect that the decision-makers prefer to reduce the uncertainty about policy outcomes in order to minimise future conflicts and ensure the successful implementation of the policy. This implies that, in the context of high polarisation, the EP would prefer to maintain more control 
over implementing agency to ensure that it adheres to the approved policy measures as much as possible. Hence, we posit that

H3: When overall polarisation around a given policy increases in the EP, the extent of delegation around legislation associated with the policy decreases.

We further expect that polarisation has a similar moderating role as salience. Specifically, we anticipate that increasing polarisation is likely to hinder the extent of delegated powers the Commission enjoys. Having overcome the decision-making gridlock, polarised legislators in the EP are likely to be cautious of empowering the Commission given their lack of control opportunities over the implementation stage of the process (Bendor \& Meirowitz, 2004). Furthermore, limited resources of the Commission cast a shadow on its capabilities to ensure the adherence to the compromise coined between the parties in the EP. Therefore, we hypothesise that

H4: When party polarisation increases, the extent of delegated powers will be more limited when the European Commission oversees implementation.

\section{Data description}

To test our hypotheses, we rely on a novel dataset containing information on delegation dynamics in the EU and on the data from the Euromanifesto project (Schmitt et al., 2018) as it provides a more detailed account of party positions across multiple policy areas. The analysis focuses on the legislation approved between 2013 and 2016 under OLP. This time frame allows us to examine delegation dynamics under two EP terms. We follow Franchino's (2007) approach and allocate legislation from the delegation dataset into ten separate groups (Table A1). This allows us to move beyond a two-dimensional representation of political decision-making and to examine the delegation decisions with more precision. It also enables us to match policy positions of the parties in the EP to a specific policy area, therefore providing detailed 
insights about the extent of power the legislators in the EU are willing to grant to the agency across policy areas.

We rely on two operationalisations of the dependent variable. The first captures the extent of delegation stipulated in the legislative act, whereas the alternative operationalisation used for the robustness checks relies on the measurement of the discretionary leeway of the agency. Our first dependent variable measures the amount of power the EU legislators grant to the actor in charge of implementation. We operationalise the extent of delegation as a proportion of the delegating provisions over the total number of meaningful provisions in the legislative act. ${ }^{5}$ Our second dependent variable, accounts for the constraints that the principals impose on the implementing agency (see Appendix). ${ }^{6}$ Thus, it allows us to examine the effect of polarisation in the EP and salience of the issue on the effective amount of the delegated power the agency has during the implementation process.

EP polarisation: The degree of polarisation of a legislative institution is grounded in the location of parties over specific issues vis-a-vis one another. The Euromanifesto project relies on political texts to identify the position of the parties. To pinpoint any changes in the positions of the parties, we follow Lowe et al. (2011) and use a log scale of scale party positions. ${ }^{7}$ We compute polarisation for each of the ten policy/issue groupings based on party positions rather than EP group positions. This is in line with previous research showing that the groups are not as disciplined as one would expect, and this is especially the case with a conscious or polarising decision (Bowler \& McElroy, 2015).

To calculate the extent of polarisation in the EP across policy areas, we rely on Dalton's Polarization Index (PI) (Dalton 2008). This index accounts for a relative position of each party in the EP along the specified dimension and for the size of the party. To account for the party size, we use the indicator of seat shares in the EP obtained by the parties.

Salience of a policy: The underlying idea of saliency theory suggests that each party will emphasise a specific aspect of a single issue within a given setting (for instance, increasing quality of education; more/less environmental protection). Consequently, as the number of mentions of a specific policy 
increases, the salience of the issue also increases (Braun et al., 2019). We use the sum of positive and negative mentions of a specific policy issue as a proportion of the total number of quasi-sentences in a party manifesto. Following the suggestion by Lowe et al. (2011), we account for a decreasing marginal effect of adding one extra mention to the manifesto by logging the proportion. The relative size of a given party influences the effect of salience on delegation as party size defines the extent of relative power parties have in the EP. To take this into account, we weigh the salience indicator by the seat share each party obtained in the EP.

Agent in charge: Commission: To test our conditional hypotheses, we construct a variable which takes a value of 1 if the Commission oversaw the implementation and 0 if the NAs were in charge. To capture the distinction in responsible agencies, we examine the number of provisions delegating power to either the Commission or the NAs. We code the case of delegation to the Commission if the number of provisions endowing it with power is strictly higher than the number of provisions empowering NAs. ${ }^{8}$

Control variables: Drawing on previous studies, we control for the extent of conflict within the Council of Ministers as it was shown to impact the extent of delegation to the EU Commission (Franchino, 2007; Pollack, 2003). We operationalise this factor using two different variables. First, we rely on the number of debates in the Council. This variable allows for capturing the extent of disagreement between the MS. Second, the literature suggests that conflict is better captured by the abstention patterns. Van Gruisen and Crombez (2019) maintain that distinguishing abstention votes and votes against a proposal allows for differentiating between different motivations for dissent: the former signal discontent but leave a room for further cooperation and compromises; the latter imply a high level of conflict and signal a resolve to oppose a legislation. In the main models we control for abstentions in the Council. For robustness checks, we additionally control for 'No votes in the Council', which allows us to capture a potential effect of a more active confrontation.

Current literature maintains that inter-principal disagreements influence the decision-making processes (Crombez \& Vangerven, 2014). Furthermore, the number of reading legislative acts passed 
through may affect the likelihood of the EP presenting a 'united front' (Hagemann \& Høyland, 2010), while early agreements and adoption of the legislative act after the first reading may indicate that the conflicts between the EP and the Council have been resolved prior to the proposal being voted on in the plenary (i.a. Farrell \& Héritier, 2004). We account for these factors by controlling for the number of readings the legislative act passed through. The variable is coded 1 if the legislation has been adopted after the first reading, signifying a lack of inter-institutional conflict.

Next, the extent of delegation to both NAs and the Commission depends on whether the EU shares the competence within a policy with the MS or rather enjoys exclusive legislative power. The Treaty on the Functioning of the EU differentiates between three categories of competencies: exclusive, shared and supporting. Official Journal publications provide an exhaustive list of policies that fall under each category (EU Publication Office, 2016). Hence, we categorise legislative acts into predefined categories.

As it is not unreasonable to anticipate differences in behaviour of parties depending on the legislative term, hence, we introduce a dichotomous variable '8th legislature term', which takes the value 1 if the legislative act has been approved during the 2014-2019 EP term.

\section{Analysis and first results}

Given that all our response variables are ratio bounded between 0 and 1, we test our hypotheses by means of a series of beta-regression models using a logit link function, with fixed effects for the policy categories and standard errors clustered on the level of policy area. ${ }^{9}$ Our dependent variable in M1-3 is the delegation ratio that captures the extent of power the principals in the EU are willing to transfer to the agency for the implementation of a policy. ${ }^{10}$ In M4 our dependent variable is a measure discretion, which accounts for the extent of control the principals exercise over the agency. We believe that this approach allows us to construct a more complete perspective on the role of policy salience and party polarisation in structuring delegation patterns in the EU. The models suggest similar patterns of the results when we utilise our dependent variables, supporting our assumption. 
Table 1. Beta-regression estimates

\begin{tabular}{|c|c|c|c|c|}
\hline & $\begin{array}{l}\text { Model 1, } \\
\text { Delegation }\end{array}$ & $\begin{array}{l}\text { Model 2, } \\
\text { Delegation }\end{array}$ & $\begin{array}{l}\text { Model 3, } \\
\text { Delegation }\end{array}$ & $\begin{array}{l}\text { Model 4, } \\
\text { Discretion }\end{array}$ \\
\hline $\begin{array}{r}\text { Agent in charge: The } \\
\text { Commission }\end{array}$ & $-0.113^{* * *}(0.035)$ & $-0.334(0.618)$ & $0.0878(0.093)$ & \\
\hline Polarization & $-3.034^{*}(1.580)$ & $-3.019^{*}(1.595)$ & $-2.779^{*}(1.591)$ & $-7.645^{* * *}(2.174)$ \\
\hline Salience & $0.457(0.557)$ & $0.511(0.530)$ & $0.507(0.577)$ & $0.542(0.779)$ \\
\hline $\begin{array}{r}\text { Polarization X Agent in charge: } \\
\text { The Commission }\end{array}$ & & & $-0.433^{* *}(0.176)$ & \\
\hline $\begin{array}{r}\text { Salience X Agent in charge: } \\
\text { The Commission }\end{array}$ & & $-0.088(0.242)$ & & \\
\hline $\mathrm{N}$ of Debates in the Council & $0.032^{* * *}(0.012)$ & $0.032^{* * *}(0.011)$ & $0.033^{* * *}(0.012)$ & $-0.096^{* * *}(0.018)$ \\
\hline Council abstentions & $0.108^{* *}(0.045)$ & $0.108^{* *}(0.046)$ & $0.105^{* *}(0.045)$ & $0.076(0.047)$ \\
\hline First reading & $0.0229(0.174)$ & $0.0211(0.174)$ & $0.0135(0.177)$ & $-0.121(0.179)$ \\
\hline Media Attention & $-0.004(0.006)$ & $-0.004(0.006)$ & $-0.004(0.006)$ & $-0.008(0.009)$ \\
\hline $8^{\text {th }}$ Legislature & $-0.055^{*}(0.029)$ & $-0.056^{*}(0.029)$ & $-0.055^{* *}(0.028)$ & $-0.034(0.118)$ \\
\hline \multicolumn{5}{|l|}{ Competence } \\
\hline Shared & $-0.033(0.109)$ & $-0.032(0.108)$ & $-0.041(0.108)$ & $0.108(0.161)$ \\
\hline Supporting & $-0.282(0.208)$ & $-0.281(0.209)$ & $-0.291(0.208)$ & $0.173(0.154)$ \\
\hline Policy Category Dummies & Yes & Yes & Yes & Yes \\
\hline Constant & $0.575(1.514)$ & $0.704(1.421)$ & $0.565(1.548)$ & $2.519(2.005)$ \\
\hline Scale Constant & $3.351^{* * *}(0.133)$ & $3.352^{* * *}(0.133)$ & $3.358^{* * *}(0.136)$ & $2.169^{* * *}(0.208)$ \\
\hline Observations & 208 & 208 & 208 & 207 \\
\hline Chi 2 & 300.954 & 65.286 & 908.47 & 1938.387 \\
\hline Log-Likelihood & 255.4833 & 255.5114 & 256.1134 & 128.6055 \\
\hline
\end{tabular}

Notes: Standard errors clustered on the level of Policy Categories are in parentheses. ${ }^{*} p<0.10,{ }^{* *} p<0.05,{ }^{* * *} p<$ 0.01

Contrary to our expectations, the results do not suggest that salience shapes the extent of delegation because its effect fails to reach statistical significance across all models. The results support our hypothesis regarding effects of polarisation $(H 3)$. In line with our conjunction, increasing polarisation in the EP hinders the extent of the delegated powers. This result indicates that having agreed upon a content of a policy, the 
parties in the EP do not quite abandon their conflictual stances and seek to limit possibilities for policy drift by limiting the influence the agent may have on the outcome. ${ }^{11}$ Previous studies have shown that party polarisation influences the decision-making process (Roger et al., 2017) when it comes to building coalitions necessary for legislative approval or introduction of the amendments to the proposed legislation. Our result signifies that the effect of polarisation transcends the policymaking stages and exerts its influence on the delegation decision. This effect of party conflict is stable across model specifications and reaffirms the expectations that, having avoided the gridlock over policy measures, the EP parties attempt to increase certainty about policy implementation by keeping the agency on a shorter leash.

Figure 1. Predicted effects of polarization
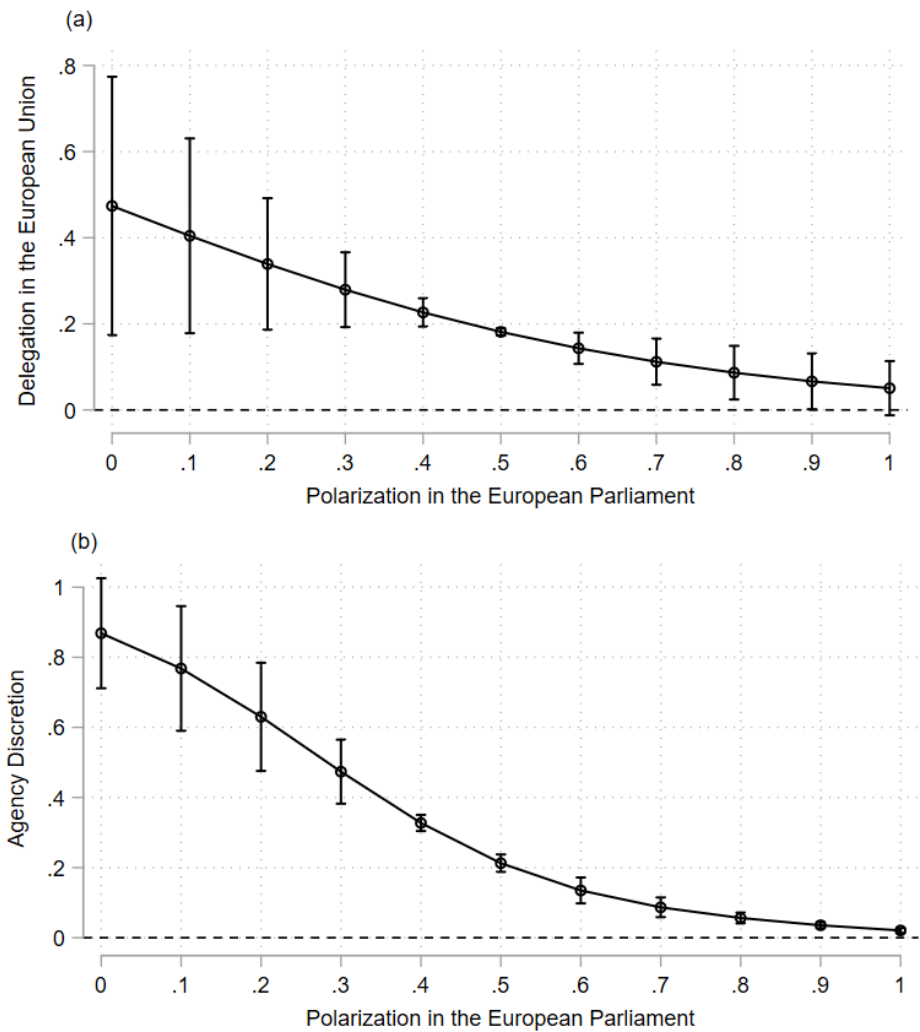

Note: Panel (a) shows predicted effects of polarization based on the estimates of Model 1; Panel (b) presents predicted effects of polarization based on Model 4. $95 \mathrm{CI}$ are included.

Compared to an unpolarised context in which the amount of delegation is around 0.5 , the delegation to the agencies can be barely distinguished from zero when polarisation reaches its maximum (i.e. around 1 Figure 
1a). The same pattern can be noted when we use the agency discretion as our dependent variable. To be more specific, in M4, we find that the effects of polarisation appear to be more curvilinear and stronger when it comes to hindering the power of the agents (Figure 1b). Substantially speaking, polarisation is the strongest predictor of the degree of both delegation and discretion.

M3 examines whether the power of the different agencies is influenced by increasing polarisation between the parties (H4). Our results paint a rather fascinating picture: not only the effect of polarisation itself suggests a reduced delegated power, but the results also point towards a difference in delegation patterns depending on the agency in charge of implementation: M3 indicates that, as the inter-party conflict grows in strength, the EP parties are willing to delegate less power when the Commission oversees the implementation in contrast to the cases in which NAs take charge. This effect is in line with our formulated expectations and suggests that having overcome their differences towards policy measures, the European parties remain sceptical about delegating powers to the Commission. In our argument, we posit that the influence of polarisation for the EU Commission is particularly curtailing because the principals lack effective control mechanisms over the actions of the Commission and thus seek to restrict the extent of power available to it. However, despite being reluctant to transfer a broad set of powers to the Commission, the principals do look for a way to ensure credible commitment to contentious policies. Figure 2 shows that, in a context of minimum polarisation, the degree of delegation is larger by approximately one percentage point when the Commission oversees implementation; this pattern changes when polarisation is low. When polarisation is close to zero, the degree of delegation is one percentage point lower when the Commission is in charge than when NAs are in charge. This latter case brings evidence supporting $H 4$, as we can note that the EP is even less likely to grant delegation prerogatives to the Commission than NAs are in cases of high polarisation. Still, we need to note that, while statically significant, these differences are substantially small. 
Figure 2. Predicted effect of delegation

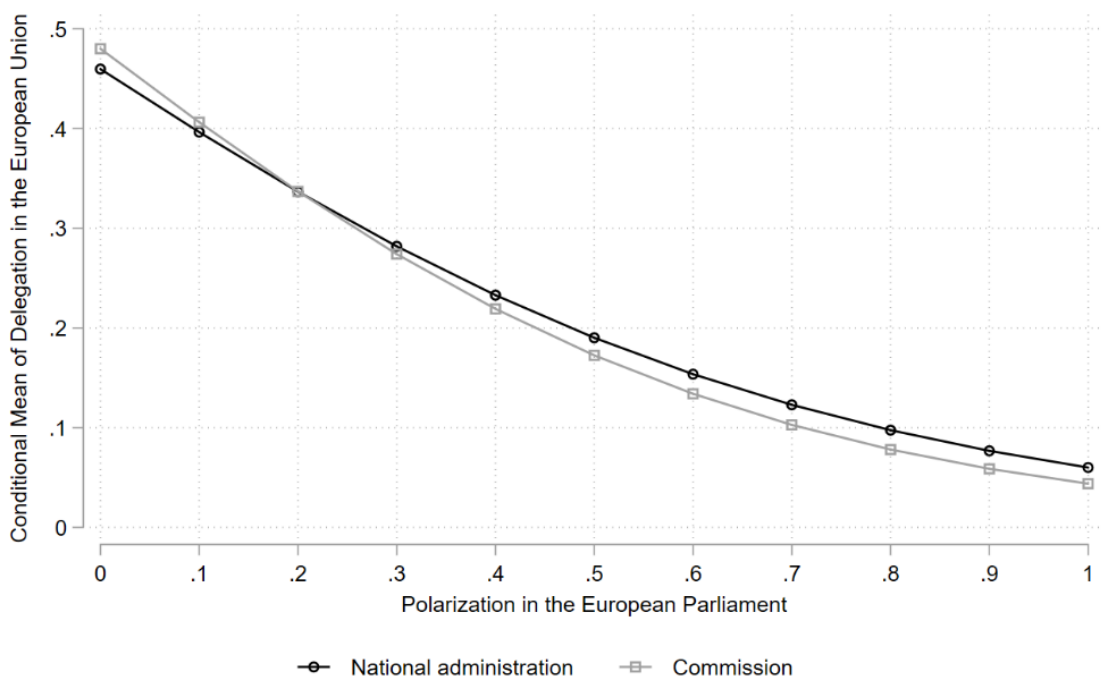

Note: estimates are based on Model 3 in Table 1

To unpack this effect, we split our sample into two subsamples. We do so by using an indicator of the agency in charge. This approach allows us to unpack any systematic differences depending on whether the Commission or the NAs oversee the implementation stage. Our dependent variables are 'discretion of the EU Commission' and 'discretion of the NAs'. By splitting the sample, we differentiate the effects that may systematically differ depending on the type of agency we focus on. The results are in line with our expectations regarding the effect of polarisation. In both models, the extent of polarisation has a negative effect on the amount of power available to the agency (Table A3). Given that all the legislative acts in the dataset fall under OLP, our findings are in line with the literature suggesting that, under co-decision, the EP systematically restricts delegation when the Commission acts as the agent (Héritier \& Moury, 2011).

Furthermore, our models point to interesting effects of the control variables. Firstly, the level of conflict in the Council shows a positive effect on the extent of delegation. However, the effect is negative when it comes to the extent of discretionary leeway available to the NAs or the Commission. This variable is significant only in Model 1-4. The direction of the effect is in line with the predictions from previous studies: as Pollack(2003) suggests, the discretion of the agency diminishes when the MS representatives 
disagree, since they seek to keep a tighter grip on the Commission. The increasing level of delegation ratio in the first three models is in line with the results presented by Franchino (2007), who suggests that disagreements within the Council are likely to increase delegation to the agency in order to insulate implementation stage from individual influences. Our other proxy for measuring conflict in the Council shows a similar effect: the abstention votes increase the extent of delegation but hinder the leeway available to the agencies. The effect is statistically sound across the models. ${ }^{12}$

Lastly, we capture differences between two legislative terms in Models 1-3. It appears that the EP has been slightly more hesitant to transfer power to the agencies for policy implementation stage in the 8 th legislative term.

For the robustness check, we use a multilevel binomial model. Here, we consider that, from a theoretical point of view, salience and polarisation may be seen as correlated indicators by some (although a pairwise correlation yields $\rho$ of 0.34). Thus, we check if their simultaneous inclusion into the models affects our results. Using a multilevel design, we consider that legislative acts that fall into a specific category and were approved under each of the EP's legislative term may share some characteristics. Our findings regarding polarisation remain intact: even when nesting legislation within the policy categories and the legislative term, the increasing conflict in the EP obstructs the extent of delegated powers available to the agency when the legislation is approved under OLP. Next, we support our findings regarding the effect of polarisation when the Commission oversees the implementation of policies (Table A7).

To challenge our results, we consider arguments regarding the importance of Grand Coalitions (GC) and Surplus Grand coalitions (SCC) in the EP for the outcome of the decision-making. Following Hix and Høyland (2013), we recalculate our measure of polarisation for parties that are likely to form GC (EPP and S\&D) or SCG (EPP and S\&D with support of ALDE). The negative effect of party polarisation remains substantial across models (Table A8-9).

We also examine whether the distance between the median of the EP and the Commission's stance may hinder the motivation to delegate power to the agents (Table A11). Furthermore, we introduce 
additional controls capturing the degree of complexity of the legislative act measured by the number of recitals and a categorical variable differentiating between the types of legislation (Table A13-14). We examine whether the amending nature of the legislation may influence our results (Table A15). We also turn to a relative measure of discretion for our DV to demonstrate the effect of polarisation (Table A16). Lastly, we calculate the margin by which the legislative proposal obtained the approval of the EP. We use this proxy to examine the effect of the conflict potentially not captured by the variable of polarisation. Our results withstand the scrutiny and offer additional support for our conjunctions regarding the polarisation effect on delegation in the Union.

\section{Conclusion}

Party politics in the EP have been in the spotlight of researchers for quite some time. However, until now the link between intra-parliamentary dynamics and delegation dynamics in the Union has not been addressed. In this contribution we offered first results suggesting that, while the salience of the policy among EP member parties does not seem to have an impact, the effects of party polarisation in the EU transcend early stages of the policymaking process and shape the delegation decisions.

Although our results are robust against various model specifications, we are aware that this contribution has some limitations. Firstly, we rely on a rather small sample of the legislative acts approved under OLP to estimate the relationship between delegation patterns and party polarisation. Therefore, we stress throughout our paper that our results hold for cases that fell under the OLP. Secondly, some may maintain that one should turn to the analysis of the roll-call votes to capture polarisation in the EP. We do not agree with this argument, as the analysis of roll-call votes $(\mathrm{RCV})$ would rather draw the attention to the issue of party discipline in the EU and the means party and party families rely on to ensure a united stance among their members. Extant studies show that the EP parties tend to be highly coherent, which further discourages us from drawing on RCV for the measurement of party polarisation (Hix et al., 2018). Lastly, lacking a fine-grained proxy to capture the potential effect of the preference convergence between the principals and

the agency leaves us in the dark regarding their prospective moderating effects on the influence of 
polarisation and possibly salience. This limitation may explain a lack of support for our saliency hypotheses, as the relative proximity of the agency may motivate the EP to delegate more power to the agent, since the costs of the prospective bureaucratic drift are non-existent. However, Bendor and Mierowitz (2004) suggest that the allied interests of the principal and the agent may not necessarily result in more power being available to the agency. In their view, an allied agent may be less cautious about shirking, because being caught deviating will hurt an agent with an outlying preference more. We attempted to control for this influence in our robustness checks, but future studies should try to develop a more comprehensive measurement of preference proximity.

Our analysis focuses on the EP, where legislation is approved by a simple majority vote. Under this rather permissive rule, the polarisation among the parties limits the power of the implementing agent. However, it is possible that increasing restrictiveness of the decision-making rule may alter the effect of the conflict between the principals. For instance, increasing a threshold to an absolute majority may strengthen parties' motivations to build a necessary coalition by compromising on the degree of flexibility on policy measures during the implementation stage. Thus, under a more restrictive decision-making rule, the principals might delegate more power to the agent to ensure flexibility of the implementation process. This possibility is in line with previous studies emphasising the motivations of the principals to delegate the power to the agents (Bendor \& Mierowitz, 2004; Franchino, 2007).

We believe that current findings have implications for studies of party behaviour and delegation, and for scholars and practitioners concerned with legislative bargaining. They highlight the influence of conflict between political elites that transcends the initial stages of decision-making and affects the outcome of policy implementation. Furthermore, we believe that our paper brings in new insights for literature concerned with collective actions and decision-making by moving beyond the idea of having a unitary legislator that counterbalances the divergent interests represented in the Council. The insights into the conflict dynamic and its consequences for delegation should motivate future contributions to reconsider the extent to which divergence of party interests shape policies in the EU. 
This article speaks to various strands of EU studies. Our results suggest that extent of conflict in the Council affects the patterns of delegation. In their contribution, Hagemann and Høyland (2010) underlined a possibility that intra-Council conflicts spill over to the parliamentary arena, affecting the extent of contention the parties exhibit. Drawing on our results, one may posit that perhaps the intra-Council conflict spill-over itself is rather a catalyst of the underlying frictions that exist in the EP due to polarised (and occasionally opposing) preferences represented by the parties. This contention offers a new avenue for research focused on tracing the links between erupting conflict on the earlier stages of decision-making to its very last stage. Future contributions should examine whether delegation dynamics are shaped by the ideological affiliations of the disagreeing Council members and whether this affects cleavage lines in the EP.

Lastly, this contribution allows for advancing the studies concerned with the patterns of coalition formations and their role in shaping outcomes of the legislative process. We posit that one should consider the decision to delegate as the step that follows the zone of danger that various coalition partners must face while bargaining over policy compromise. We demonstrate that, in the case of delegating decisions, the extent of polarisation even within a GC or SGC plays a critical role in defining the extent of agency powers. This in turn further emphasise our crucial point that the omission of this stage of decision-making leaves a substantial gap in the current studies. Arguments suggesting that GC or SGC are decisive for the policy outcome omit the key component linking the de jure legislation with its de facto outcome, namely the extent of powers the agency enjoys as it allows the agent to adjust policies while implementing them.

\section{Acknowledgements:}

We would like to thank the three anonymous reviewers and editors of the Journal for their helpful comments and suggestions. We are also thankful to Bjørn Høyland, Moritz Osnabrügge, and panel participants of EPSA 2019 and EPOP 2019 for their feedback on earlier versions of the article. 


\section{Replication materials}

Supporting data and materials for this article can be accessed on the Taylor \& Francis website.

\section{Authors:}

Anastasia Ershova is an LSE Fellow at the Department of Government, London School of Economics and Political Science, UK. Her research interests include decision-making processes and delegation the EU, comparative and bureaucratic politics.

Sebastian Adrian Popa is a lecturer in Comparative Politics at Newcastle University, a research fellow at the Mannheim Centre for European Social Research (MZES), and a core team member of the European Election Studies. His research interests include political behaviour, public opinion, political knowledge, European Parliament elections, political communication via social media and party politics.

\section{Notes}

${ }^{1}$ We posit that the EP and the Council may opt to empower either the Commission or the NAs to ensure policy implementation (see i.a. Franchino, 2007).

${ }^{2}$ We implicitly assume throughout the paper that the Council does not explicitly oppose the legislation.

${ }^{3}$ When the NAs oversee the implementation process, the Commission acts as the Guardian of the Treaties, ensuring a proper implementation, thus increasing the number of controls over the process. Our focus is on the overall opportunities of the EU principals to control the agencies, and not on comparison of mechanisms available to the EP vis-à-vis the Council.

${ }^{4}$ Similar results were formally and empirically presented by Epstein and O’Halloran(1999).

${ }^{5}$ DELEGATION $N_{i}=\sum \frac{D_{i}}{P_{T}}$., where Di is a delegation provision to either the Commission or NA. 
6 We measure discretion with the formula $d_{i}=\frac{D_{i}}{P_{D+C}}-\left(\frac{C_{i}}{T_{i}} * \frac{D_{i}}{P_{D+C}}\right)$, where $d_{i}$ stands for discretion and $D_{i}$ signifies a number of delegating provisions; $P_{D+C}$ stands for the number of provisions that indicate either delegation to the executive agent or/and the constraints imposed. $C_{i}$ denotes a number of constraints imposed on the executive for the national administration and for the Commission and $T_{i}$ is a total number of possible constraints.

${ }^{7}$ Exact formula: $\theta^{d}=\log \left(d^{+}+0.5\right)-\log \left(d^{-}+0.5\right)$, where $d^{+}$indicates positive statements of the party on the issue and $d^{+}$- negative statements on the issue.

${ }^{8}$ For a similar approach see Franchino (2007).

${ }^{9}$ We obtained almost identical results using fractional outcome regression models.

10 We checked for potential selection bias, but neither polarisation nor salience impact the choice of the implementing agency (Table A9). We do not use a selection model in which polarisation and salience first influence the choice of implementing agency and impact the extent of delegation only in a second step.

${ }^{11}$ We examine whether the effect of polarisation is susceptible to the removal of outliers. The effect is robust to these changes (Table A4).

12 Following Hagemann and Høyland (2010), we test whether extent of Council disagreements affects the effects of polarised parties (Table A10). 


\section{References}

Aspinwall, M.D., \& Schneider, G.(2000). Same Menu, Seperate Tables: The Institutionalist Turn in Political Science and the Study of European Integration. European Journal of Political Research, 38(1), 1-36.

Bawn, K.(1997). Choosing Strategies to Control the Bureaucracy: Statutory Constraints, Oversight, and the Committee System. Journal of Law, Economics, and Organization, 13(1), 101-126.

Bendor, J., \& Meirowitz, A.(2004). Spatial Models of Delegation. The American Political Science Review, 98(2), 293-310.

Bouwen, P.(2009). The European Commission. In D. Coen \& J. J. Richardson (Eds.), Lobbying the European Union: Institutions, actors, and issues (pp. 19-38). Oxford University Press.

Bowler, S., \& McElroy, G.(2015). Political group cohesion and 'hurrah' voting in the European Parliament. Journal of European Public Policy, 22(9), 1355-1365.

Braun, D., Popa, S.A., \& Schmitt, H. (2019). Responding to the crisis: Eurosceptic parties of the left and right and their changing position towards the European Union. European Journal of Political Research, 58(3), 797-819.

Calvert, R.L., McCubbins, M.D., \& Weingast, B.R.(1989). A Theory of Political Control and Agency Discretion. American Journal of Political Science, 33(3), 588-611.

Crombez, C., \& Vangerven, P.(2014). Procedural models of European Union politics: Contributions and suggestions for improvement. European Union Politics, 15(2), 289-308.

Dalton, R.J.(2008). The Quantity and the Quality of Party Systems: Party System Polarization, Its Measurement, and Its Consequences. Comparative Political Studies, 41(7), 899-920.

Egeberg, M., \& Trondal, J.(2009). Political Leadership and Bureaucratic Autonomy: Effects of Agencification. Governance, 22(4), 673-688.

Epstein, D., \& O’Halloran, S.(1994). Administrative procedures, information, and agency discretion. American Journal of Political Science, 38(4), 697-722.

Epstein, D., \& O’Halloran, S.(1999). Delegating powers: A transaction cost politics approach to policy making under separate powers. Cambridge University Press. 
Ershova, A.(2018). The Watchdog or the Mandarin? Assessing the impact of the Directorates General on the EU legislative process. Journal of European Public Policy, 1-21.

European Union Publication Office.(2016). Division of competences within the European Union. http://eur-lex.europa.eu/legal-content/EN/TXT/?uri=LEGISSUM:ai0020\&qid=1508857350904

Farrell, H., \& Héritier, A.(2004). Interorganizational Negotiation and Intraorganizational Power in Shared Decision Making: Early Agreements Under Codecision and Their Impact on the European Parliament and Council. Comparative Political Studies, 37(10), 1184-1212.

Franchino, F.(2000). The Commission's Executive Discretion, Information and Comitology. Journal of Theoretical Politics, 12(2),155-181.

Franchino, F.(2002). Efficiency or credibility? Testing the two logics of delegation to the European Commission. Journal of European Public Policy, 9(5),677-694.

Franchino, F.(2007). The Powers of the Union. Delegation in the EU. Cambridge University Press. Gormley, W.T.(1986). Regulatory Issue Networks in a Federal System. Polity, 18(4),595-620.

Gruisen, P.V., \& Crombez, C.(2019). National parliamentary control and voting in the Council of the European Union. European Journal of Political Research, 58(3),981-1000.

Hagemann, S., \& Høyland, B.(2010). Bicameral Politics in the European Union: Bicameral Politics in the European Union. Journal of Common Market Studies, 48(4),811-833.

Héritier, A., \& Moury, C.(2011). Contested Delegation: The Impact of Co-decision on Comitology. West European Politics, 34(1),145-166.

Hix, S., \& Noury, A.(2009). After Enlargement: Voting Patterns in the Sixth European Parliament. Legislative Studies Quarterly, 34(2),159-174.

Huber, J.D., \& Shipan, C.R.(2002). Deliberate Discretion?: The Institutional Foundations of Bureaucratic Autonomy. Cambridge University Press.

Klüver, H., \& Spoon, J.-J.(2015). Bringing salience back in: Explaining voting defection in the European Parliament. Party Politics, 21(4),553-564.

Koop, C.(2011). Explaining the Accountability of Independent Agencies: The Importance of Political Salience. Journal of Public Policy, 31(2),209-234. 
Lowe, W., Benoit, K., Mikhaylov, S., \& Laver, M.(2011). Scaling Policy Preferences from Coded Political Texts: Scaling Policy Preferences from Coded Political Texts. Legislative Studies Quarterly, 36(1),123-155.

Majone, G.(2001). Two Logics of Delegation: Agency and Fiduciary Relations in EU Governance. European Union Politics, 2(1),103-122.

Pollack, M.A.(2003). The Engines of European Integration: Delegation, Agency, and Agenda Setting in the EU. Oxford University Press.

Price, D.E.(1978). Policy Making in Congressional Committees: The Impact of "Environmental" Factors. American Political Science Review, 72(2),548-574.

Rittberger, B.(2000). Impatient legislators and new issue-dimensions: A critique of the Garrett-Tsebelis standard version' of legislative politics. Journal of European Public Policy, 7(4),554-575.

Roger, L., Otjes,S., \& van der Veer, H.(2017). The financial crisis and the European Parliament: An analysis of the Two-Pack legislation. European Union Politics, 18(4),560-580.

Schmitt, H., Braun, D., Popa, S.A., Mikhaylov, S., \& Dwinger, F.(2018). European Parliament Election Study 1979-2014, Euromanifesto StudyEuropean Parliament Election Study 1979-2014, Euromanifesto Study [Data set]. GESIS Data Archive. https://doi.org/10.4232/1.12830

Schneider, G., Finke, D., \& Bailer, S.(2010). Bargaining Power in the European Union: An Evaluation of Competing Game-Theoretic Models. Political Studies, 58(1),85-103.

Sinclair, B.(2006). Party wars: Polarization and the politics of national policy making. University of Oklahoma Press.

Tallberg, J.(2002). Delegation to Supranational Institutions: Why, How, and with What Consequences? West European Politics, 25(1),23-46.

Thomson, R.(2008). National Actors in International Organizations The Case of the European Commission. Comparative Political Studies, 41(2),169-192.

Thomson, R.(2011). Resolving Controversy in the European Union: Legislative Decision-Making Before and After Enlargement. Cambridge University Press. 
Thomson, R., \& Torenvlied, R.(2011). Information, Commitment and Consensus: A Comparison of Three Perspectives on Delegation in the European Union. British Journal of Political Science, 41(01),139-159. 